\title{
Do boato à lenda. Comunicação informal e fronteiras identitárias nas origens da controvérsia donatista
}

\author{
Rumour into legend. Informal communication and identity \\ boundaries at the origins of the Donatist controversy
}

\section{Julio Cesar Magalhães de Oliveira*}

RESUMO

Muito já se escreveu sobre as origens da controvérsia donatista como uma memória reconstruída em contextos posteriores ou, ao contrário, como um conjunto de fatos, que embora obscuros, poderiam ser reconstituídos pela crítica documental. Pouco se considera, porém, as ambiguidades que já estavam presentes desde o início nas percepções dos cristãos africanos e que contribuíram para a construção dessas memórias divergentes. O objetivo deste artigo é avaliar os diferentes usos que os rumores, os boatos e as conversas informais tiveram na eclosão da controvérsia donatista e entender o processo que elevou essas histórias de estatuto ainda incerto à condição de crenças que justificavam e delimitavam as fronteiras identitárias entre os cristãos africanos.

Palavras-chave: Memória social. Identidade. Controvérsia donatista.

\section{ABSTRACT}

Much has been written about the origins of the Donatist controversy as a memory reconstructed in later contexts or, inversely, as a set of facts which, although obscure, could be reconstituted through a critical reading of sources. But the ambiguities in the perceptions of African Christians that were already present

\footnotetext{
* - Possui graduação em História pela Universidade Estadual de Campinas (1998), mestrado em História Social pela Universidade Estadual de Campinas (2001) e doutorado em História e Arqueologia do Mundo Antigo pela Université Paris Ouest Nanterre La Défense, antiga Université Paris X Nanterre (2006). De 2008 a 2013 foi professor de História Antiga da Universidade Estadual de Londrina. Atualmente, é professor de História Antiga da Universidade de São Paulo. Tem experiência na área de História, com ênfase em História Antiga, atuando principalmente nos seguintes temas: História Romana, Antigüidade Tardia, África romana, Trabalho e movimentos sociais urbanos e Cristianismo antigo.
} 
at the beginning of the schism and that contributed to the construction of these divergent memories must also be considered. The purpose of this article is to evaluate the different uses of rumours at the outbreak of Donatist controversy and understand the process that raised these stories to the status of beliefs that justified and delimited the identity boundaries between African Christians.

Keyword: Social memory. Identity. Donatist controversy.

Uma das consequências mais duradouras da última perseguição aos cristãos no Império Romano, a perseguição de Diocleciano de 303 a 305, foi a divisão permanente da Igreja no Norte da África em dois campos opostos e concorrentes. Na origem da disputa, estavam as acusações mútuas de traição suscitadas pelas suspeitas de colaboração dos clérigos cristãos com as autoridades perseguidoras para entrega e destruição das Escrituras e do mobiliário eclesiástico, em cumprimento ao primeiro edito da Grande Perseguição (Eusebius Caesariensis, $H E$ 8, 2, 4; Lactantius, Mort. Persec. 12-13, apud DE STE CROIX, 1954). É em razão dessas suspeitas que o bispo de Cartago, Ceciliano, eleito para suceder o bispo Mensúrio em 306 ou 307, foi logo contestado por aqueles que o acusavam de ter colaborado com os perseguidores ou, ao menos, de ter sido ordenado por um colaborador. Recusando-se a reconhecer a validade de sua ordenação, elegeram em seu lugar a Majorino, a quem Donato, pouco depois, sucedeu. ${ }^{1}$

As circunstâncias precisas dessa ruptura que dividiu os cristãos africanos ao longo dos séculos IV e V entre "cecilianistas" e "donatistas" permanecerão para sempre obscuras, devido à escassez de documentos contemporâneos dos próprios acontecimentos e aos usos polêmicos que deles fizeram os partidários de ambos os grupos muitas décadas depois, na época de Optato e de Agostinho (BARNES, 1975, p. 13). Mas as incertezas que cercavam esses fatos não eram menores para aqueles que os haviam vivenciado. Convocado a testemunhar diante do governador da Numídia em Cirta (Constantina), em 320, no julgamento de um dos bispos que haviam consagrado Majorino como opositor de Ceciliano, Vítor, o gramático, dizia não saber muito mais sobre as razões do conflito:

Eu mesmo não conheço a causa da divisão; sou apenas um fiel no meio do povo cristão. Sei apenas que, quando eu estava em Cartago, dizia-se que o bispo Segundo, quando veio a Cartago certa vez, soube que Ceciliano, não sei por que, tinha sido consagrado bispo incorretamente e, por isso, instituiu outro bispo no lugar dele. Foi daí que começou a divisão em Cartago, mas não posso saber ao certo qual foi a causa dessa divisão, porque nossa

1 A data da eleição episcopal de Ceciliano e de seu adversário Majorino tem sido objeto de controvérsia. Adoto aqui a datação proposta por Barnes (1975) e Lancel (1979) e aceita, em suas linhas gerais, por Shaw (2011, p. 812-819). Para os argumentos em favor de uma cronologia mais curta, que situa a eleição de Ceciliano em 311 ou 312 , isto é, pouco antes da intervenção de Constantino, ver Monceaux (1912, p. 8-21) e Frend (1951, p. 15-21). 
cidade, como sempre, só tem uma lgreja e, se aqui já houve divisão, nós não sabemos de nada. (GESTA apud ZENOPHILUM, 17a, CSEL 26, p. 185). ${ }^{2}$

O depoimento de Vítor ocorria no momento mesmo em que o primeiro imperador cristão, Constantino, tendo esgotado todos os esforços de conciliação entre as partes, decidia, pela primeira vez, suprimir a divisão pela força e em favor dos partidários de Ceciliano (FREND, 1951, p. 159-162; DUVAL, 2000, p. 184-203). No longo prazo, a memória dessa repressão e os conflitos violentos que se seguiram entre as facções contribuiriam para consolidar suas fronteiras identitárias e elevar suas versões dos fatos ao estatuto de lendas ou, se preferirmos, de mitos de origem. Em 320, porém, a disputa ainda parecia a Vítor um assunto localizado, fundado antes em suspeitas do que em certezas e no que "ouviu dizer".

Muito já se escreveu sobre as origens da controvérsia donatista como uma memória reconstruída em contextos posteriores ou, ao contrário, como um conjunto de fatos, que embora obscuros, poderiam ser reconstituídos pela crítica documental. ${ }^{3}$ Pouco se considera, porém, as ambiguidades que já estavam presentes desde o início nas percepções dos cristãos africanos e que contribuíram para a construção dessas memórias divergentes. Meu objetivo neste artigo é avaliar os diferentes usos que os rumores, os boatos e as conversas informais tiveram na eclosão da controvérsia donatista e entender o processo que elevou essas histórias de estatuto ainda incerto à condição de crenças que justificavam e delimitavam as fronteiras identitárias entre os cristãos africanos.

\section{Boato e memória}

A relação entre boato e memória, que aqui pretendo investigar, era uma evidência para os antigos, a começar pelo vocabulário. Afinal, gregos e romanos podiam designar pela mesma palavra (seja ela a $\varphi n ́ \mu \eta$, para os primeiros, ou a fama, para os latinos) tanto o boato incerto, como a reputação consolidada, tanto o rumor passageiro, como a memória transmitida pela tradição (HARDIE, 2012, p. 3). No seu sentido etimológico, a palavra latina fama deriva do verbo fari, que significa falar, dizer, a partir de fando, "o que se diz", "o que se ouve dizer" (ERNOUT; MEILLET,

\footnotetext{
2 "Ego dissensionis originem nescio; unus sum de populo christianorum. Siquidem cum essem apud Carthaginem, Secundus episcopus cum Carthaginem tandem aliquando uenisset, dicuntur inuenisse Caecilianum episcopum nescio quibus non recte constitutum, illi contra alium instituerunt. Inde illic apud Carthaginem coepta dissensio est et inde originem scire dissensionis plene non possum, quoniam semper ciuitas nostra unam ecclesiam habet et, si habuit dissensionem, nescimus omnino". Todas as traduções dos textos latinos citados neste artigo são de minha autoria.

3 Entre as tentativas de reconstituição da primeira fase da controvérsia donatista, ver Kriegbaum (1986) e Rossi (2013, p. 85-181). Sobre as apropriações posteriores da memória do cisma, ver Dearn (2004) e Shaw (2011, p. 66-106).
} 
1967, p. 214). Ela designava, portanto, em primeiro lugar, o processo de transmissão de uma informação pela conversa, pelo boca-a-boca (o rumor, os sermones) e, de modo mais geral, toda notícia de caráter incerto. Num segundo sentido, fama significava não mais o processo de transmissão, mas o seu resultado. Tratava-se aqui da opinio uulgi, da existimatio hominum, isto é, da opinião pública ou do julgamento das pessoas (positivo ou negativo) a respeito de um evento ou de uma pessoa conhecida. Daí se segue a conotação mais positiva de reputação como um patrimônio adquirido por uma pessoa a partir daquilo que se diz a seu respeito e tudo o que é comumente dito ou celebrado sobre pessoas, coisas, reinos ou povos do passado ou do presente. Por fim, mas não menos importante, a fama podia ser personificada como um mensageiro, a exemplo da Fama representada por Virgílio como um monstro alado com tantos olhos, línguas e ouvidos quantas plumas pelo corpo (Aen. 4, 173-181). Nesse sentido, fama é aquela que anuncia, celebra ou destrói as reputações no presente e que transmite aos pósteros a memória e a glória das coisas passadas. $^{4}$

A própria multiplicidade de sentidos da palavra fama está, portanto, a nos indicar um aspecto central para a compreensão de boatos e memórias: em ambos os casos, trata-se tanto de uma forma narrativa, como de um processo de transmissão. Mas ao contrário do tom moralizante da última acepção da palavra, que tanta fortuna teve na tradição ocidental e nos estudos modernos, é preciso também lembrar que rumores, boatos e memórias não são forças autônomas e externas aos indivíduos, mas práticas que não podem ser dissociadas das intenções e disposições daqueles que se comunicam. ${ }^{5}$ As memórias, por exemplo, não são independentes dos indivíduos, pois afinal são eles que se recordam. Mas elas só se tornam sociais quando os indivíduos compartilham suas lembranças em um contexto específico. Nas palavras de James Fentress e Chris Wickham (1992, p. 8):

As recordações que partilhamos com outros são aquelas que são relevantes para eles, no contexto social de determinado tipo, quer seja estruturado e duradouro (uma família; a força de trabalho de uma fábrica; uma aldeia) ou informal e possivelmente temporário (um grupo de amigos que frequenta o mesmo bar; um grupo que organiza jantares).

O mesmo ocorre com os boatos e rumores. O portador de um boato não o enuncia em qualquer lugar, nem diante de qualquer pessoa, mas apenas quando encontra um quadro propício à interação e à confidência (ALDRIN, 2005, p. 54). É apenas quando se sente estar entre cúmplices ("cá entre nós") é que se dispõe a revelar seu segredo.

4 Sobre as diferentes acepções da palavra latina fama na Antiguidade, ver ThLL, s.v. fama, col. 206-227. Sobre o vocabulário grego sobre os boatos e a reputação (LARRAN, 2010).

5 Sobre as imagens da fama na tradição ocidental (HARDIE, 2012). Sobre os estudo da memória social nas ciências humanas, ver Peralta (2007). Para os boatos (ALDRIN, 2003). 
Boatos, rumores e memórias fazem parte, portanto, daqueles momentos da interação social em que os atores sociais confrontam e avaliam os eventos passados, presentes ou iminentes e estabelecem ou reforçam suas identidades sociais. Em todos os casos, trata-se sempre de uma busca ativa e coletiva de significado. Os boatos, já o disse Tamotsu Shibutani, são o resultado de uma deliberação coletiva, da busca de informações diante da escassez de notícias ou da desconfiança em relação à verdade oficial (SHIBUTANI, 1966). A memória social, do mesmo modo, não é um receptáculo passivo, mas um processo ativo de reestruturação das lembranças no seio de um dado grupo social. Boatos são aceitos porque fazem sentido para a experiência de vida daqueles que os compartilham. Existe memória social porque há significado para o grupo que 0 recorda (FENTRESS; WICKHAM, 1992, p. 112). E todas as vezes que um boato se consolida em crença e torna-se parte da memória é porque um grupo social específico se empenhou em salvar do esquecimento a "sua" versão dos fatos (ALDRIN, 2005, p. 244).

Para reconstituir o caminho social dos boatos até sua consolidação numa memória narrada é preciso, então, analisar as intenções de seus portadores, o contexto de sua enunciação e as razões de sua credibilidade e de sua preservação entre aqueles que os compartilham. Boatos podem ter usos diversos e sentidos diferentes, dependendo dos atores que os promovem e das situações em que se encontram. Recorrer aos canais clandestinos e a uma forma impessoal e anônima de apresentar uma informação pode ser tanto uma estratégia deliberada de atacar um rival evitando o embate direto, como uma forma espontânea de confrontar e avaliar as informações disponíveis. Nas situações rotineiras, os boatos podem ser vistos como parte constituinte da sociabilidade quotidiana. Nesse contexto, eles servem tanto para reafirmar os laços sociais e consolidar ou ajudar a construir as identidades, articulando as clivagens entre "nós" e "eles", quanto para contornar os interditos, ao permitir a seus enunciadores dizerem o que de outro modo lhes seria inconveniente, em decorrência de sua posição ou de seu papel social. Nas situações de forte tensão (como em momentos de guerras, catástrofes ou crises políticas), esses mesmos mecanismos são amplificados e a troca de boatos permite aos atores presentes "exprimir um sentimento latente, compartilhar suas opiniões e reinterpretar espontaneamente os eventos (ou as situações) inquietantes" (ALDRIN, 2005, p. 80).

Enquanto informação paralela e, algumas vezes, oposta à informação oficial, o boato pode ser visto como um contra-poder (KAPFERER, 1993, p. 16). Mas, na maior parte dos casos, ele é apenas uma entre outras fontes de informação. A extensão de sua difusão depende, portanto, da capacidade das autoridades ou dos promotores habituais de notícias de avalizar ou, ao contrário, desqualificar a informação clandestina (ALDRIN, 2005, p. 84; 271). Mas quando a ordem das certezas é abalada e a credibilidade das autoridades ou dos promotores de notícias é subvertida, os boatos podem se tornar uma verdade alternativa. Quando essa verdade se torna indispensável à própria identidade de um grupo, a sua versão dos fatos pode parecer aos seus membros mais verossímil do que qualquer versão oficial. É então, e só então, que ela pode perpetuar-se no tempo e se transformar numa contra-memória. 


\section{A fama da traição}

Nas disputas que cercaram a sucessão episcopal em Cartago, em 306 ou 307, ou nas lutas posteriores pelo reconhecimento da legitimidade de cada grupo após a intervenção do imperador Constantino, os boatos foram muitas vezes usados de forma calculada e estratégica pelos chefes de cada partido e para seus próprios fins. Mas na origem da disputa já se encontravam as histórias de traição que circulavam desde a época da perseguição. Ao contrário de seus usos posteriores, essas histórias haviam sido formuladas e utilizadas de forma muito mais espontânea pelos fiéis antes mesmo de serem apropriadas por seus líderes. Como Agostinho de Hipona devia reconhecer no Salmo Abecedário contra os Donatistas, uma canção popular que ele compôs em 392 para ser cantado pelos membros mais humildes de sua comunidade, no princípio, tudo o que havia era a fama:

Porque já havia se espalhado a fama/da entrega das Escrituras

Os que eram seus autores/ escondiam-se na confusão.

Então a outros difamaram/ para a si mesmos se ocultarem.

(Augustinus, Psalmus Contra Partem Donati, vv. 66-68, BA 28, p. 158-160). ${ }^{6}$

Como Brent Shaw ressaltou recentemente, há uma hipocrisia nessas palavras que pode ter passado despercebida ao próprio Agostinho. Afinal, a acusação que Agostinho fazia aos donatistas era a mesma que os donatistas faziam aos bispos de seu partido: a de que atacavam seus adversários para esconder as culpas de seu próprio campo (SHAW, 2011, p. 81). Para além desse jogo de acusação e contra-acusação, no entanto, é sugestivo que Agostinho reconhecesse que, antes que qualquer partido tivesse iniciado esse processo de difamação deliberada, "já havia se espalhado a fama da traição".

O contexto em que circulavam esses primeiros rumores era, portanto, o das conversas informais entre fiéis sobre a atitude dos bispos e de outros clérigos diante da perseguição. No dia-adia de uma comunidade religiosa, as conversas sobre as atitudes dos clérigos eram parte daquela sociabilidade quotidiana pela qual os que dela participam estreitam os laços que os unem, ao mesmo tempo em que apontam a distância que os separam de seus líderes e exprimem suas expectativas em relação a eles. Na estrutura hierárquica da comunidade cristã, a figura do bispo era

6 "Quia fama iam loquebatur/ de librorum traditione./ Sed qui fecerant latebant/ in illa perturbatione./ Inde alios infamarunt/ ut se ipsos possent celare". 
tida como a de um "guardião do povo", aquele que vigia, o responsável por assegurar a disciplina dos clérigos e da comunidade, a probidade da administração e a pureza doutrinal da Igreja. Enquanto "pais" e "pastores", esperava-se dos sacerdotes uma conduta de absoluta pureza. Não é por acaso que as acusações habituais dos paroquianos contra clérigos e bispos até a época de Agostinho versassem sempre sobre os aspectos que manchavam ou se desviavam dessa imagem: a avareza, a improbidade, o comportamento sexual indevido, a embriaguez e a gula (SHAW, 2011, p. 350-355).

Em tempos normais, boatos como esses podiam ser contrabalançados pela capacidade dos bispos de desqualificar essas notícias, graças ao monopólio da palavra autorizada que detinham e ao controle de toda uma rede de informações de que dispunham. Como Agostinho o disse certa vez a seus fiéis: "Depois deste meu sermão, as pessoas vão continuar falando. Mas o que quer que falem, ao menor vento que sopre, algo chegará a meus ouvidos" (AUGUSTINUS, 356). ${ }^{7}$ No entanto, na situação de crise aberta pela perseguição, as condições mesmas que favoreciam esse controle se viram subitamente subvertidas pela dúvida radical sobre o comprometimento dos líderes, suspeitos de traírem a Deus e à comunidade cristã. ${ }^{8}$ Nesse contexto de incertezas, a hierarquia dos "regimes de verdade" é perturbada e as suspeitas que recaem sobre os clérigos tornam-se para muitos cristãos mais verdadeiras do que qualquer justificativa apresentada pelos acusados. ${ }^{9}$

Muitas das acusações de traição feitas a bispos e outros clérigos por seu comprometimento com as autoridades perseguidoras derivavam menos da atestação cabal nas atas públicas de que tivessem entregue os livros sagrados ou sacrificado aos deuses pagãos do que de sua atitude ambígua diante dos mandatos imperiais. O bispo Félix de Abtugnos, por exemplo, o principal consagrador de Ceciliano, pode não ter participado pessoalmente do ato de entrega das Escrituras, como o comprovaria anos mais tarde o duúnviro responsável à época pela operação de busca e apreensão. O único documento em que se mencionava de forma explícita a sua colaboração revelou-se no julgamento de sua causa em 315 ter sido deliberadamente falsificado por um inimigo seu, o escriba municipal Ingêncio. Mas foi seu afastamento providencial da cidade no dia mesmo em que os funcionários públicos se dirigiram a sua casa para cumprir o mandato imperial o que deu origem às conversas de que o bispo e o duúnviro teriam entrado em acordo. Não se pode nem mesmo descartar que essas conversas fossem, de início positivas, pois elas bem podiam ser um

7 "Post sermonem meum locuturi sunt homines, sed quodlibet homines loquantur, qualicumque aura flante, perducentur inde aliquid aures meas".

8 Recentemente, Rebillard (2012, p. 34-60) levantou dúvidas sobre o impacto das perseguições no Norte da África, por ressaltar que o pertencimento à confraria cristã não era necessariamente o elemento mais relevante de suas identidades no dia-a-dia. Isso é certamente verdade, mas eu concordo com Shaw (2014, p. 936) que "algo que ataque frontalmente as ideias fundamentais e exija uma decisão sobre a identidade parece muito mais problemático". Os cristãos podiam se conformar às requisições das autoridades, mas isso não quer dizer que essa conformidade deixasse de representar um real traumatismo para eles ou para os demais membros da comunidade.

9 O conceito de "regimes de verdade" é definido por Foucault (2012, p. 98) como "os tipos de informação que ligam as manifestações da verdade aos seus procedimentos e os sujeitos que são seus operadores, testemunhos ou eventualmente objetos". Para Aldrin (2005, p. 87), as situações em que os mecanismos de regulação social desaparecem ou parecem desaparecer perturbam a hierarquia dos regimes de verdade porque tornam 0 universo social imprevisível, aumentam a fluidez social da informação e negam os promotores habituais de notícias. É nesses contextos que os boatos se tornam a fonte privilegiada de informação sobre o evento ou a situação social vivenciada. 
comentário sobre a astúcia do bispo. Mas foi esse o pretexto que seus inimigos utilizaram mais tarde para acusá-lo de traição. ${ }^{10}$

O mesmo pode ser dito do bispo Mensúrio de Cartago, que foi acusado de ser um traditor, isto é, um "entreguista", por ter se utilizado de um ardil para evitar o cumprimento do mandato imperial, substituindo os livros sagrados por escritos heréticos para serem levados pelas autoridades. Em uma carta enviada a seu colega Segundo de Tígisis, o então primado da Numídia, Mensúrio parece ter justificado sua atitude como uma forma de evitar toda provocação. A carta foi lida na íntegra pelos donatistas mais de um século depois, no terceiro dia da Conferência de Cartago de 411 entre os dois episcopados africanos, para provar a culpa do antecessor de Ceciliano. Como esse trecho das atas se perdeu, hoje conhecemos o teor da carta apenas pelo testemunho indireto de Agostinho, que convém aqui transcrever:

Naquela epístola, parecia que Mensúrio confessava o seu crime. Ele, no entanto, não escrevia que entregara os santos códices, mas antes que os havia retirado e escondido para que os perseguidores não os encontrassem. Deixara, no entanto, na basílica dos Nove alguns escritos reprováveis dos heréticos para que os perseguidores os encontrassem e os levassem e nada mais the pedissem. Escrevia, no entanto, que alguns homens da ordem [dos decuriões?] de Cartago haviam depois levado ao conhecimento do procônsul que os enviados para confiscar e queimar as Escrituras dos cristãos haviam sido enganados, porque não encontraram nada do que lhes competia requisitar. Aquelas, na verdade, estavam guardadas na casa do bispo, de onde deveriam retirar e queimar. O procônsul, porém, não quis consentir nessa nova requisição. Naquela mesma carta, pôde-se ainda ler que Mensúrio desaprovava e proibia os cristãos de honrarem aqueles que se entregavam às perseguições sem terem sido detidos e que, além disso, diziam ter as Escrituras, sem que Ihes tivessem sido requisitadas, apenas para não entregá-las. Naquela mesma epístola, eram também acusados alguns delinquentes e devedores do fisco que, vendo na perseguição uma ocasião, ou buscavam libertar-se de uma vida de muitas dívidas, ou procuravam reabilitar-se e até lavar-se de seus crimes, ou ainda pensavam conseguir algum dinheiro e usufruir na prisão dos donativos oferecidos pelos cristãos. No entanto, os donatistas acusavam Mensúrio apenas do crime de entrega dos códices. Diziam, portanto, que ele havia mentido ao dizer que os códices entregues não eram santos e que tentava esconder o seu pecado,

10 Acta purgationis Felicis, f. 26a (CSEL 26, p. 199, I. 18-19): "Cum ad domum eiusdem Felicis episcopi mitteremus, renuntiauerunt officiales publici illum absentem esse". Sobre as relações amistosas entre o bispo Félix e o duúnviro Alfio Ceciliano, ver Lepelley (2001, p. 321-328). Sobre o depoimento do duúnviro e o documento falsificado por Ingêncio, um inimigo pessoal de Félix, ver Duval (2000, p. 247-288). 
embora eles também lhe recriminassem a própria encenação. (AUGUSTINUS, Brev. Coll. III, 13, 25). ${ }^{11}$

Agostinho, como se vê, tentava conduzir a leitura dessa carta para demonstrar que ela não apresentava nenhuma prova contra Mensúrio. Mensúrio "parecia que confessava seus crimes", mas ele "não escrevia que entregara os santos códices". Agostinho também fazia crer que a acusação dos donatistas portava apenas sobre a entrega dos verdadeiros códices, embora reconhecesse ao final que eles também recriminavam a própria encenação. A resposta do bispo Segundo, que Agostinho reportava em seguida, parece, no entanto, contestar precisamente o subterfúgio utilizado por Mensúrio:

\begin{abstract}
Segundo escrevia ainda que, quando um centurião e um soldado beneficiário foram enviados até ele por ordem do curador e da ordem [dos decuriões] com o objetivo de requisitar os códices divinos para serem queimados, ele respondera: "Sou cristão e bispo, não um traidor". E quando Ihe pediram que entregasse um livro apócrifo ou qualquer outra coisa para levarem, nem isso ele thes deu, seguindo o exemplo de Eleazar, o Macabeu, que não quis nem fingir comer carne suína para não servir aos outros de exemplo de
\end{abstract} prevaricação. (AUGUSTINUS, Brev. Coll. III, 13, 25). ${ }^{12}$

Como se vê, Segundo parecia contrapor seu próprio exemplo ao de Mensúrio, o que sugere que as suspeitas que pesavam contra o bispo de Cartago e que haviam chegado ao conhecimento do primado da Numídia derivavam antes da percepção de que o subterfúgio da troca dos livros não deixava de implicar um acordo e, portanto, alguma forma de colaboração com as autoridades perseguidoras.

\footnotetext{
11 "In qua epistola uidebatur Mensurius uelut de suo crimine confiteri: qui tamen non scripserat se sanctos codices tradidisse, sed potius ne a persecutoribus inuenirentur abstulisse atque seruasse; dimisisse autem in basilica Nouarum quaecumque reproba scripta haereticorum, quae cum inuenissent persecutores et abstulissent, nihil ab illo amplius postulasse. Verumtamen quosdam Carthaginiensis ordinis uiros postea suggessisse proconsuli, quod illusi fuerant qui missi erant ad Christianorum Scripturas auferendas et incendendas, quia non inuenerant nisi nescio qua ad eos non pertinentia; ipsas autem in domo episcopi custodiri, unde deberent proferri et incendi: proconsulem uero ad hoc eis consentire noluisse. In eisdem etiam litteris lectum est, eos qui se offerrent persecutionibus non comprehensi, et ultro dicerent se habere Scripturas, quas non traderent, a quibus hoc nemo quaesierat, displicuisse Mensurio, et ab eis honorandis eum prohibuisse Christianos. Quidam etiam in eadem epistola facinorosi arguebantur et fisci debitores, qui occasione persecutionis uel carere uellent onerosa multis debitis uita, uel purgare se putarent, et quasi abluere facinora sua, uel certe adquirere pecuniam, et in custodia deliciis perfrui de obsequio Christianorum. Crimen tamen Donatistae non ingerebant Mensurio, nisi de codicibus traditis: mentitum eum quippe dicebant, quod illi non fuerint codices sancti, et peccatum suum tegere uoluisse; quamuis et ipsam fictionem criminarentur."

12 "Scripsit etiam Secundus, et ad se ipsum missos a curatore et ordine centurionem et beneficiarium, qui peterent diuinos codices exurendos, eisque respondisse: 'Christianus sum et episcopus, non traditor'. Et cum ab eo uellent aliqua ecbola, aut quodcumque accipere; neque hoc eis dedisse, exemplo Eleazari Macchabaei, qui nec fingere uoluit suillam carnem se manducare, ne aliis praeberet praeuaricationis exemplum". Adoto aqui a tradução proposta por Rossi

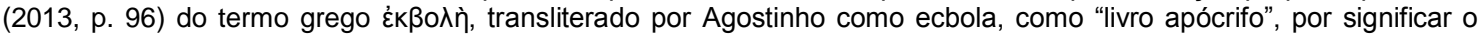
que é expulso, o que é rejeitado e que talvez seja um eco do termo usado por Mensúrio para se referir aos escritos heréticos deixados na basílica dos Nove como reproba.
} 
No entanto, como Alessandro Rossi observou em um estudo recente, é notável que a carta de Mensúrio não justificasse o expediente da troca dos volumes por livros heréticos. Sua preocupação principal era justificar seu posicionamento diante da veneração dos fiéis pelos mártires e confessores na prisão (ROSSI, 2013, p. 97-98). Essa era, sem dúvida, outra razão de suspeita entre alguns dos cristãos de Cartago. De fato, são essas determinações de Mensúrio para controlar o acesso aos mártires que parecem estar na origem de outro boato que circulava desde a época da perseguição e que nos é reportado mais uma vez por Agostinho ao se referir à leitura na Conferência de 411 das atas do concílio presidido por Segundo de Tígisis que contestou a eleição de Ceciliano:

E os donatistas leram então as atas do concílio de cerca de setenta bispos reunido em Cartago contra Ceciliano, no qual o condenaram, em sua ausência, porque ele não quis vir até eles, sob a acusação de ter sido ordenado por traidores e porque se dizia que, quando era ainda diácono, teria proibido que os mártires na prisão recebessem alimento. Foram nomeados ainda alguns colegas de Ceciliano, que as atas públicas atestariam terem sido traidores, embora essas atas não tenham sido lidas. Entre eles, Félix de Abtugnos era o mais duramente atacado, pois se dizia que era "a fonte de todos os males". (AUGUSTINUS, Brev. Coll. III, 14, 26). ${ }^{13}$

A ênfase de Agostinho neste trecho procura ressaltar as acusações formais de traição feitas aos consagradores de Ceciliano, mas a leitura deste documento nos mostra o peso que também era atribuído, na origem da controvérsia, aos rumores sobre a atuação do diácono de Mensúrio, segundo os quais Ceciliano "teria proibido que os mártires na prisão recebessem alimento". São eles, afinal, que explicam a rejeição a Ceciliano em sua própria comunidade. O que precisamos saber é por que esse boato mobilizava a opinião de tantos cristãos em Cartago. Todo boato retira sempre sua verossimilhança da realidade imediata e seu poder simbólico de um fundo imaginário comum àqueles que o partilham (ALDRIN, 2005, p. 29). Os diáconos eram os responsáveis pelo aprovisionamento de alimentos aos confessores aprisionados e é isso que tornava o boato verossímil. Ceciliano, além disso, já havia se notabilizado pela aparente dureza com que se posicionava, antes mesmo da perseguição, diante das formas de devoção que ligavam os cristãos aos seus mártires, ao repreender em público a nobre Lucila por sua prática de beijar o osso de um mártir antes de receber a eucaristia (OPTATUS, I, 16, 1 apud ROSSI, 2013, p. 103-112). Mas se a história de sua recusa em alimentar os confessores na prisão mobilizava os cristãos de Cartago é

13 "Et recitatum est a Donatistis concilium ferme septuaginta episcoporum contra Caecilianum apud Carthaginem factum, ubi eum absentem damnauerunt, quod ad eos uenire noluerit; tamquam a traditoribus ordinatus, et quia cum esset diaconus, uictum afferri martyribus in custodia constitutis prohibuisse dicebatur. Nominati sunt etiam quidam collegae Caeciliani qui traditores asserebantur publicis gestis, quae tamen gesta non legebantur. Inter hos autem maxime Felix Aptugnensis acerbius accusatus est, ita ut 'fons malorum omnium' diceretur”. 
porque ela falava de perto a uma preocupação recorrente nessa comunidade, pelo menos desde o final do século II, de que os futuros mártires fossem alimentados em abundância enquanto estivessem no cárcere para que, como patronos espirituais, eles pudessem garantir benefícios, presentes ou futuros, para a comunidade e os indivíduos que se dirigiam a eles (MACGOWAN, 2003).

Mensúrio pode, portanto, ter agido por prudência ou esperteza ao substituir os livros sagrados por heréticos, mas seu ardil também podia ser interpretado como prevaricação. O controle das visitas podia ser uma forma de garantir a preeminência do poder eclesiástico face a essa fonte concorrente e independente de santidade que eram os mártires (BOURRIT, 2008, p. 455), mas ela também podia ser interpretada como uma forma de traição. $E$ é em razão dessa ambiguidade que muitos cristãos podiam acreditar que o diácono Ceciliano estivesse pouco interessado em manter o vínculo de solidariedade que unia a comunidade a seus mártires e que não apenas controlasse, mas de fato impedisse que os alimentos chegassem aos confessores na prisão.

\section{Os boatos espalhados pelo ódio}

Num primeiro momento, portanto, os boatos sobre a traição de Mensúrio, Ceciliano, Félix e outros clérigos surgiram como especulações espontâneas sobre a ambiguidade de suas atitudes, num contexto de intensa demanda dos fiéis por referências e de sua inquietação quanto ao futuro de sua própria comunidade. Essas mesmas histórias, no entanto, seriam instrumentalizadas mais tarde nas lutas sucessórias e nos acertos de contas que se seguiram ao fim da perseguição provavelmente já desde maio de 305, quando Constâncio tornou-se Augusto no Ocidente (BARNES, 2010, p. 150). Em Cartago, a disputa pela sucessão do bispo Mensúrio, opôs de início as facções de Bôtro e Celéstio, e, em seguida, as de Ceciliano e Majorino. Mas apenas quando Ceciliano, como bispo eleito e consagrado, entrou em confronto com os seniores, os notáveis da comunidade, foi que seus adversários, unidos agora contra o inimigo comum, parecem ter-se empenhado ativamente numa campanha para destitui-lo, recorrendo, para isso, aos rumores sobre sua atuação como diácono e sobre o comprometimento de seus consagradores durante a perseguição. No concílio de setenta bispos reunido em Cartago e presidido por Segundo de Tígisis, foram esses boatos, como vimos, que garantiram a sua condenação (KRIEGBAUM, 1986, p. 96 129).

Com a consagração de Majorino em oposição a Ceciliano, cada facção passou a buscar o apoio das demais comunidades cristãs africanas com uma campanha ativa de convencimento. Cartas circulares foram enviadas a todas as comunidades. Viajantes e mercadores foram recrutados para espalhar notícias. Um desses difusores, o escriba municipal Ingêncio, um inimigo pessoal do 
bispo Félix de Abtugnos, seria acusado pelo advogado do partido de Ceciliano em um julgamento em 315 de ter espalhado a sedição por todas as igrejas pelas quais passou enquanto circulava a negócios pelas Mauritânias e pela Numídia: "dignai-vos perguntar a ele com a autoridade de quem, com qual dolo, com qual loucura ele percorreu todas as Mauritânias e ainda as Numídias e por qual razão comoveu as igrejas católicas levando-as à sedição" (Acta purgationis Felicis, 28b, CSEL 26, p. 203). ${ }^{14}$ Foi por esses meios, segundo Optato de Mileve, que "os falsos boatos chegaram aos ouvidos de todos e a fama da mentira se espalhou entre os povos" (OPTATUS, I, 20). ${ }^{15}$ Optato condenava os métodos usados pelos partidários de Majorino, mas é possível que os cecilianistas adotassem os mesmos recursos.

A circulação dos boatos de traição por toda a África não teria, porém, o mesmo efeito que em suas localidades de origem, como Cartago e Abtugnos. De fato, os fiéis das demais cidades não conheciam pessoalmente os personagens envolvidos e viam-se, portanto, menos implicados na disputa. Isso explica porque os boatos aí tivessem menor impacto e menor persistência, como o sugere o testemunho de Vítor, o gramático, citado no início deste texto, que, vivendo em Cirta e ainda em 320, dizia não saber ao certo qual a causa da divisão. Em Cartago, porém, o longo intervalo que se seguiu entre a controversa sucessão episcopal, em 306 ou 307, e a intervenção de Constantino, no inverno de 312 a 313, contribuiria, nas palavras de Agostinho, para que "os falsos boatos ganhassem consistência com o passar do tempo, como se a disputa já tivesse sido julgada por uma antiga opinião pública" (Ep. 43, 7, 18, CSEL 34/2, p. 100). ${ }^{16}$

A vitória de Constantino contra Maxêncio, em 312, e sua decisão de favorecer a Igreja cristã mudariam, porém, o contexto dessas disputas. ${ }^{17}$ Reconhecendo Ceciliano e seus partidários como os únicos "católicos" a quem as propriedades confiscadas durante a perseguição deveriam ser restituídas e outros benefícios concedidos (EUSEBIUS CAESARIENSIS, HE 10, 5, 15-17; 10, 6 e 10, 7), o imperador obrigou os partidários de Majorino a embarcarem numa luta por seu reconhecimento como cristãos. Em 15 de abril de 313, o procônsul Anulino já relatava ao imperador ter recebido "algumas pessoas acompanhadas de uma multidão do povo julgando deverem se opor a Ceciliano”. Na ocasião, entregaram-Ihe dois documentos. Um deles, anônimo, devia tratar-se das atas do concílio presidido por Segundo de Tígisis. O outro, porém, era um libelo intitulado "Denúncia da Igreja Católica contra os crimes de Ceciliano trazida pela parte de Majorino". ${ }^{18}$ Desde então, a mobilização da opinião pública e, portanto, dos boatos, das histórias que se contavam, passaria a ter um papel central nas estratégias de defesa dos adversários de Ceciliano, que agora precisavam justificar a legitimidade de sua posição.

\footnotetext{
14 "Apronianus dixit: dignare de eo quaerere, qua auctoritate, quo dolo, qua insania circuierit Mauritanias omnes, Numidias etiam, qua ratione seditionem commouerit catholicae ecclesiae."

15 "[...] ut rumoribus falsis cunctorum auribus infererent, mendacium sparsa fama per populos".

16 "[...] falsis rumoribus temporis diuturnitate firmatis quasi uetusta fama praeiudicante"

17 Sobre a entrada em cena de Constantino e o sentido inicial de sua intervenção, ver Rossi (2013, p. 127-165).

18 Relatio Annulini, apud Augustinus, Ep. 88, 2 (CSEL 34/2, 408): "[...] uerum post paucos dies extiterunt quidam adunata secum populi multitudine, qui Caeciliano contradicendum putarent quique fasciculum in aluta signatum et libellum sine signo obtulerunt dicatione meae atque impendio postularunt, ut ad sacrum ac uenerabilem comitatum numinis uestri dirigerem, quae manente Caeciliano in statu suo subiectis eorundem actis, quo cuncta maiestas uestra possit dinoscere, paruitas mea dirigere curauit. Transmissi libelli duo, unus in aluta suprascriptus ita: "Libellus ecclesiae catholicae criminum Caeciliani traditus a parte Maiorini”, item alius sine sigillo cohaerens eidem alutae [...]".
} 
Esses novos usos, mais defensivos, das histórias de traição que circulavam em Cartago seriam mais tarde lembrados por Agostinho ao recomendar a seus adversários donatistas a leitura das atas, hoje perdidas, do embate entre Ceciliano e Donato, então recém-eleito como sucessor de Majorino, na conferência presidida pelo bispo de Roma Melquíades na Domus Faustae (a futura basílica do Latrão), em 2 de outubro de 313, para decidir com qual dos dois bispos as igrejas transmarinas deviam comunicar:

Leiam e considerem tudo isso. Vejam com quanto cuidado de conservar ou restituir a paz e a unidade tudo isso foi discutido: como foi tratada a pessoa dos acusadores e por quais máculas foram recusados os testemunhos de alguns deles. Vejam como, pelas palavras dos presentes, ficou constatado que eles mesmos não tinham nada a dizer contra Ceciliano, mas que queriam transferir toda a causa à plebe do partido de Majorino, isto é, a uma multidão sediciosa e afastada da Igreja. Queriam que Ceciliano fosse acusado por essa turba e só por seus clamores de revolta. Acreditavam, assim, poder desviar a seu bel prazer os ânimos dos juízes, sem que nenhum documento atestasse o que diziam e sem que a verdade fosse examinada. Como se uma multidão furiosa e embriagada pelo erro e pela corrupção pudesse dizer a verdade ao acusar Ceciliano de qualquer crime, quando setenta bispos (o que aconteceu no caso de Félix de Abtugnos) puderam agir com tanta temeridade ao condenar colegas ausentes e inocentes! Da mesma forma que aqueles bispos haviam concordado com uma turba para condenar inocentes sem interrogá-los, assim também queriam que Ceciliano fosse condenado por uma turba semelhante. Mas, desta vez, eles não encontraram juízes que se deixassem persuadir por aquela demência! (AUGUSTINUS, Ep. 43, 5, 14, CSEL 34/2, p. 96-97). ${ }^{19}$

$\mathrm{Na}$ interpretação de Agostinho, como vemos, o recurso dos acusadores de Ceciliano aos "clamores de revolta" da "multidão sediciosa" era uma forma de evitar o jogo de argumento contra argumento e a apresentação de provas. Os donatistas apresentavam apenas o testemunho dos laicos, daquilo que se dizia sobre Ceciliano, mas nenhuma prova escrita, nenhum documento oficial.

19 "Legite et considerate omnia. Videte, quanta cura pacis atque unitatis conseruandae uel restituendae cuncta discussa sint, quem ad modum accusatorum persona tractata et quorundam eorum quibus maculis inprobata sit praesentiumque uocibus liquido constiterit nihil eos habuisse, quod in Caecilianum dicerent, sed totam causam in plebem de parte Maiorini, hoc est seditiosam et ab ecclesiae alienatam multitudinem transferre uoluisse, ut ab ea uidelicet turba Caecilianus accusaretur, quam solis tumultuosis clamoribus nulla documentorum adtestatione, nullo ueritatis examine ad suam uoluntatem animos iudicium detorquere posse arbitrabantur, nisi forte furiosa et poculo erroris atque corruptionis ebria multitudo uera in Caecilianum crimina diceret, ubi septuaginta episcopi, sicut de Felice Aptungitano constitit, absentes et innocentes collegas tam insana temeritate damnarunt. Quali enim turbae illi consenserant, ut aduersus innocentes non interrogatos proferrent sententias, a tali turba etiam rursus accusari Caecilianum uolebant. Sed non plane tales inuenerant iudices, quibus illam dementiam persuaderent!" 
O que o bispo de Hipona, no entanto, não reconhecia é que a força adquirida pela opinião pública contra Ceciliano em Cartago era um argumento poderoso na própria África: em sua própria cidade "todos diziam" que Ceciliano era um "traidor". Essa era uma certeza que não podia ser abalada por provas, ainda mais quando o julgamento da causa era percebido, de antemão, como parcial e ambíguo. Afinal, o próprio bispo Melquíades era tido como um colaborador, suspeito de ter entregue as Sagradas Escrituras e sacrificado aos deuses durante a perseguição (AUGUSTINUS, De unico baptismo, XVI, 27).

Derrotados no julgamento do Latrão, em 313, e no concílio de Arles, em 314, Donato e seus partidários recorreriam sucessivas vezes ao imperador em Roma, Brescia e Milão. Em 316, Constantino acabou por enviar a Cartago uma comissão formada por dois bispos italianos para investigar as causas da divisão, que encontrou durante todos os dias a oposição barulhenta dos partidários de Donato (OPTATUS, I, 26). Durante todo esse tempo, Donato e Ceciliano permaneceram na Itália. Mas a decisão do imperador de reter Ceciliano em Brescia contribuiria, mais uma vez, para alimentar a ambiguidade, dando origem a novos boatos. Desde então e até a época de Agostinho, os donatistas continuariam a afirmar que o próprio imperador havia reconhecido a culpa de Ceciliano, pois dizia-se que o havia condenado ao exílio naquela ocasião (AUGUSTINUS, C. Cresc. III, 69, 79 e 71, 83).

\section{A verdade escondida}

Em 15 de fevereiro de 315, o bispo Félix de Abtugnos foi inocentado numa investigação judicial ordenada por Constantino. Em 10 de novembro de 316, o próprio imperador concluiu pela legitimidade da consagração de Ceciliano como bispo de Cartago. Em 8 de dezembro de 320, o julgamento pelo governador da Numídia do bispo Silvano de Cirta, que com outros havia consagrado Majorino em oposição a Ceciliano, concluiu, ao contrário, por sua culpa pela entrega do mobiliário eclesiástico durante a perseguição. Os documentos oficiais que resultaram desses processos foram cuidadosamente arquivados pelos partidários de Ceciliano em um dossiê de provas contra seus adversários que, em parte, chegou até nós (BARNES, 1975; DUVAL, 2000). O problema, como lembra Brent Shaw (2011, p. 83), é que esses documentos não eram nada evidentes, nem na condenação, nem na absolvição de ninguém. Quando a versão oficial não é suficiente, quando não há consenso, mas apenas a imposição de uma verdade, o que era um boato se transforma, para aqueles que se veem mais implicados, numa contraversão, numa verdade alternativa. Embora os partidários de Donato tivessem perdido todas as batalhas judiciais, eles sempre poderiam dizer que toda a verdade não havia sido dita ainda, que as questões de fundo haviam sido evitadas e que sua versão dos fatos ainda permanecia a mais provável (AUGUSTINUS, C. Cresc. III, 72,84-78,89). 
A tentativa imperial de suprimir a divisão pela força, de 317 a 321, apenas contribuiria para ampliar a dimensão do cisma, fazendo com que os cristãos de todas as igrejas se vissem agora implicados pessoalmente na divisão iniciada em Cartago (sobre essa primeira repressão, ver FREND, 1951, p. 159-162). Para dar sentido à sua situação, para explicar quem eles eram e por que estavam certos, as histórias de traição contadas desde a época da perseguição tornaram-se, então, vitais. Nas conversas quotidianas, as dúvidas dos primeiros tempos se tornavam certezas, porque eram elas que legitimavam a existência de cada grupo. Ainda na época de Agostinho, o bispo de Hipona devia notar como os fiéis das duas Igrejas, quando se encontravam nas ruas, opunham uns aos outros suas próprias versões do que havia acontecido durante a perseguição: "Irmãos, em cada esquina vocês ouvirão as suas acusações gritantes: 'Este homem foi um traidor e aquele outro também traiu'." (AUGUSTINUS, En. in Ps. 95, 11). Ou ainda: "Aquele homem entregou os livros!" "Não!" "Mas eu digo que ele entregou os livros!" (AUGUSTINUS, S. 88, 19, 22).

Nas primeiras décadas do século $\mathrm{V}$, a história da traição de Ceciliano seria mais uma vez reinterpretada pelo autor donatista da Paixão dos Mártires de Abitina. Nessa narrativa hagiográfica, escrita após a Conferência de Cartago de 411 e possivelmente em resposta a ela (DEARN, 2004), Ceciliano e Mensúrio eram agora apresentados não apenas como colaboracionistas, mas como verdadeiros perseguidores:

Foi quando Mensúrio, o assim-chamado bispo de Cartago, poluído pela recente entrega das escrituras, arrependendo-se da loucura de seus crimes, começou a tornar público crimes ainda piores. Ele que deveria pedir e implorar aos mártires o perdão pela queima dos livros, para que seus delitos fossem cumulados de escândalos ainda maiores, enfurecia-se contra os mártires com o mesmo ânimo com que havia entregue as divinas leis. Mais furioso que um tirano, mais cruel que um carrasco, ele escolheu Ceciliano como seu diácono e ministro apropriado para seus crimes e o postou na porta do cárcere armado de correias e chicotes para afastar da entrada e saída todos os que traziam alimentos e bebidas para os mártires no cárcere, ferindo ainda mais aqueles que já haviam sido prejudicados pela grave injustiça. $E$ eram atacados por todos os lados os que vinham para alimentar os mártires. Os vasos para os confessores sedentos e acorrentados no interior eram quebrados no limiar do cárcere. Os alimentos eram lançados de um lado e de outro para serem espalhados pelos cães. Fora do cárcere, jaziam os pais dos mártires e suas mães santíssimas. Excluídos da visão de seus filhos, eles passavam em vigília noite e dia na entrada da prisão. E era terrível o choro e acerbo o lamento de todos os que lá estavam, por serem proibidos de abraçarem os mártires piedosos e cumprirem o dever da piedade cristã pelo 
furioso tirano e cruel carrasco, Ceciliano. (Passio Saturnini, Datiui et al. = Acta Abitinensium, 20). ${ }^{20}$

As imagens utilizadas neste texto para descrever Mensúrio e Ceciliano associam-nos tanto aos "imperadores tiranos" que haviam decretado as perseguições, como aos carrascos representados nas atas e paixões dos mártires. A ação de Ceciliano, que quebrava os vasos e lançava aos cães os alimentos trazidos aos confessores, também evocava os rituais de profanação do período, com a mesma conotação de horror pela violação do sagrado. ${ }^{21}$ Nos anos que se seguiram à supressão autoritária do cisma depois da Conferência de Cartago de 411, essa reinterpretação polêmica das acusações contra Ceciliano era uma resposta à situação em que as comunidades donatistas se encontravam, com sua organização colocada na ilegalidade e suas basílicas e propriedades confiscadas em benefício de seus rivais. Ela era uma mensagem para tempos difíceis, uma forma de reforçar a identidade donatista como "a verdadeira Igreja Católica, aquela que sofre a perseguição, não a que persegue" (Gesta Conl. Carth. 3, 258).

Não há dúvida, como defende Alan Dearn (2004), que a Paixão dos Mártires de Abitina não pode ser tomada como uma fonte de informações sobre os fatos que marcaram as origens do cisma. Mas isso não quer dizer que a memória que ela articula nessa narrativa não tivesse relações com aquele passado. A memória social não é estável como informação, pois os fatos podem ser filtrados ou perdidos na transmissão. Mas ela o é ao nível dos significados partilhados e das imagens recordadas (FENTRESS; WICKHAM, 1992, p. 79). Na memória dos donatistas, Ceciliano havia se tornado há muito tempo mais um significado corporalizado do que um ser de carne e osso. Nas palavras de Brent Shaw (2011, p. 74-75):

Quer tenha merecido ou não, Ceciliano foi marcado com a mancha da traição, como o foram os homens que o ordenaram como bispo. Aqui também a repulsa tornou-se tão profunda que seu próprio nome foi fixado na memória e evitado como uma praga na sequência. Nenhum dissidente é encontrado portando o nome de Ceciliano desde sua ordenação como bispo. Outros

20 "[...] cum iam Mensurius, Carthaginis quondam episcopus, recenti scripturarum traditione pollutus post paenitendam sui sceleris amentiam peiora coepisset facinora publicare; quippe qui ambustorum ueniam librorum a martyribus poscere atque implorare debuerat; ut delicta sua flagitiis maioribus cumularet, eo animo saeuiebat in martyres quo diuinas traditerat leges. Etenin tyranno saeuior, carnifice crudelior, idoneum sceleris ministrum diaconum suum elegit Caecilianum eumdemque loris ac flagris armatum ante fores carceris ponit ut ab ingressu atque aditu cunctos qui uictum potumque in carcere martyribus afferrebant graui affectus iniuria propulsaret. Et caedebantur a Caeciliano passim qui ad alendos martyres ueniebant; sitientibus intus in uinculis confessoribus pocula frangebantur ante carceris limina, cibus passim lacerandus canibus spargebatur. lacebant martyrum patres ante carceris fores matresque sanctissimae et ab extremo conspectu liberorum exclusi graues noctu dieque uigilias ad ostium carceris exercebant. Erat fletus horribilis et acerba omnium qui aderant lamentatio, prohiberi a complexu martyrum pios et diuelli a pietatis officio christianos, Caeciliano saeuiente tyranno et crudeli carnifice."

21 Sobre esses rituais de profanação, associados, em especial, à tomada das basílicas por grupos cristãos rivais, ver Shaw (2011, p. 171-173). 
bispos católicos e altos funcionários "pagãos" do período portavam o nome, mas nenhum dissidente jamais o perpetuou.

Mais de um século após o início do cisma, as histórias de traição originadas na Grande Perseguição continuavam, portanto, a ser vitais para muitas comunidades donatistas. Evocadas e articuladas em modos e contextos diferentes, elas ainda constituíam o "quadro mitológico" que justificava sua existência como grupo. Mas, por essa época, elas já haviam deixado de ser aquelas notícias improvisadas, narradas sempre no condicional, que são os boatos e rumores para adentrar em definitivo nos domínios da lenda.

\section{Agradecimentos}

Uma versão preliminar deste texto foi apresentada no V Colóquio do LEIR em Vitória-ES e tenho muito a agradecer aos comentários e sugestões da audiência, em especial os de Fábio Faversani, Norberto Luiz Guarinello, Fábio Duarte Joly, Carlos Machado e Gilvan Ventura da Silva. Agradeço também aos dois pareceristas ad hoc da Revista Antíteses pelos comentários e sugestões feitos ao texto. A responsabilidade pelas ideias aqui expressas restringe-se, contudo, ao autor.

\section{Referências}

ALDRIN, P. Penser la rumeur: une question discutée des sciences sociales. Genèses, Paris, v. 50, p. 126-141, mar. 2003.

ALDRIN, P. Sociologie politique des rumeurs. Paris: PUF, 2005.

BARNES, T. Early christian hagiography and roman history. Tübingen: Mohr Siebeck, 2010. (Tria Corda 5).

BARNES, T. The beginnings of donatism. Journal of Theological Studies, Oxford, v. 26, p. 13-22, 1975. 
BOURRIT, B. Martyrs et reliques en occident. Revue de L'histoire des Religions, Paris, v. 225, n. 4, p. 443-470, 2008.

DE STE CROIX, G. E. M. Aspects of the Great Persecution. Harvard Theological Review, Cambridge, v. 47, p. $75-113,1954$.

DEARN, A. The abitinian martyrs and the outbreak of the donatist schism. The Journal of Ecclesiastical History, v. 55, n. 1, p. 1-18, 2004.

DUVAL, Yvette. Chrétiens d'Afrique à l'aube de la paix constantinienne: les premiers échos de la grande persécution. Paris: Institut d'Études Augustiniennes, 2000.

ERNOUT, A.; MEILLET, A. Dictionnaire étymologique de la langue latine: histoire des mots. 4. ed. Paris: Klincksieck, 1967.

FENTRESS, J.; WICKHAM, C. Memória social: novas perspectivas sobre o passado. Tradução de Telma Costa. Lisboa: Teorema, 1992.

FOUCAULT, Michel. Du gouvernement des vivants: cours au college de France (1979-1980). Paris: EHESS, Gallimard; Seuil, 2012.

FREND, W. H. C. The Donatist church: a movement of protest in Roman North Africa. Oxford: Oxford University Press, 1951.

HARDIE, P. Rumour and renown: representations of fama in western literature. Cambridge: Cambridge University Press, 2012.

KAPFERER, J. N. Boatos: o mais antigo mídia do mundo. Tradução de Ivone da Silva Ramos Maya. Rio de Janeiro: Forense Universitária, 1993.

KRIEGBAUM, B. Kirche der traditoren oder kirche der märtyrer: die vorgeschichte des donatismus. Innsbruck - Wien: Tyrolia Verlag, 1986.

LANCEL, S. Les débuts du donatisme: la date du «Protocole de Cirta » et de l'élection épiscopale de Silvanus. Revue des Études Augustiniennes, Paris, v. 25, p. 217-229, 1979.

LARRAN, F. Le bruit qui vole: histoire de la rumeur et de la renommée en Grèce ancienne. Toulouse: Presses Universitaires du Mirail, 2010.

LEPELLEY, C. Chrétiens et païens au temps de la persécution de Dioclétien: le cas d'Abthugni. In: Aspects de l'Afrique romaine: les cités, la vie rurale, le christianisme. Bari: Edipuglia, 2001. p. 321-328. 
MACGOWAN, A. Discipline and diet: feeding the martyrs in roman carthage. The Harvard Theological Review, Cambridge, v. 96, n. 4, p. 455-476, Oct. 2003.

MONCEAUX, Paul. Histoire littéraire de l'Afrique chrétienne depuis les origines jusqu'à l'invasion arabe. Paris: Le Donatisme, 1912. v. 4.

PERALTA, E. Abordagens teóricas ao estudo da memória social: uma resenha crítica. Arquivos da Memória, Lisboa, v. 2, p. 4-23, 2007.

REBILLARD, É. Christians and their many identities in late antiquity, North Africa, 200-450 CE. Ithaca: Cornell University Press, 2012.

ROSSI, A. Muscae moriturae Donatistae circumvolant: la costruzione di identità "plurali" nel cristianesimo dell'Africa Romana. Milano: Ledizioni, 2013.

SHAW, B. D. Being christian in North Africa. Journal of Roman Archaeology, Michigan, v. 27, p. 934936, 2014.

SHAW, B. D. Sacred violence: African christians and sectarian hatred in the age of augustine. Cambridge: Cambridge University Press, 2011.

SHIBUTANI, T. Improvised news: a sociological study of rumor. Indianapolis: Bobbs Merrill, 1966.

Recebido em 04.08.2015 - aprovado em 01.10.2015. 